American Journal of Biochemistry and Biotechnology 4 (1): 57-60, 2008

ISSN 1553-3468

(C) 2008 Science Publications

\title{
Prostate cancer incidence in Golestan province, Iran (2004)
}

\author{
${ }^{1}$ Abdoljalal Marjani and ${ }^{2}$ Mohammad Javad Kabir \\ ${ }^{1}$ Department of Biochemistry and Biophysic, Golestan University of Medical Sciences \\ ${ }^{2}$ Department of Social Medicine, Golestan University of Medical Sciences
}

\begin{abstract}
Prostate cancer is the most common cancer in men and therefore represents a major problem in public health.The aim of this study was to find and evaluate province-specific estimate of incidence in males by age groups for prostate cancer in Golestan province, Iran. The data used in this study were collected in a cancer registry program that was conducted by Health Deputy of Golestan province in IRAN for a period of 1 year (2004). Prostate cancer data was identified and collected in the population based cancer registries through the 18 Pathology Laboratories (where male populations referred to these centers) and using a structured questionnaire, trained personnel conducted in-person interviews to collect information on prostate cancer in Golestan province. Prostate cancer incidence among males in Golestan province was 5.17/100000 in gerenal. But the highest rate (ASR: 215.87/100,000) among males were showen to be in age 80-85. The incidence of prostate cancer in age 80-84 has risen sharply and it was the lowest in age 50-54 (ASR: 5.18/100,000). According to this information Golestan province harbor a rather incidence for prostate cancer (in age 80-84), comparable to the lower incidence rate reported in the world. For the present time it can be said that prostate cancer in males appear to be one of the most prevalent and serious type of cancer in Golestan province.
\end{abstract}

Key words: Prostate cancer incidence - Golestan province - Iran

\section{INTRODUCTION}

At present, cancer is a serious public health problem in many countries of the world, imposing a large economical and psychological burden as well as loss of life and productivity ${ }^{[1]}$. Lots of effort and money have been put in the fields of clinical, epidemiological, pharmacological, and biological research on cancer in the recent decades. Cancer is the third most common cause of death in Iran and annually 30000 of Iranian die due to cancer $^{[2]}$. It is estimated that more than 70000 new cases of cancer occur in the country and it is estimated that the cancer incidence in next decade suspected to be increased due to increase in elderly population within the country ${ }^{[3]}$. Prostate cancer is the second leading cause of male cancer death in most industrialized countries [4].It is the most common cancer diagnosed among men in the United States. In 2005, an estimated 232,090 new cases diagnosed and 30,350 men will die from prostate cancer in the United States ${ }^{[5]}$. African-Americans have the highest reported rates of prostate cancer in the world (With a worldwide incidence of 25.3 per 100,000), with an age-adjusted rate of 137 per 100,000 , which is 60 times higher than the reported incidence in Shanghai, China, where the reported incidence is the lowest in the world (2 per $100,000)^{[6-7]}$. The distribution of cancers vary significantly from country to country all over the world. The latest estimates of global cancer incidence show that prostate cancer is the sixth most common cancer in the world, the third most common cancer in men, the most common cancer in men in Europe, North America, and some parts of Africa with half a million new cases each year, almost $10 \%$ of all cancers in men ${ }^{[8-10]}$. Prostate cancer incidence is characterized by a very large geographical variability. Asian countries have much lower rates of occurrence of the disease than North American, and north and western European countries, with southern European and South American countries displaying an intermediate incidence rate ${ }^{[11]}$. Japanese and Chinese men are less likely to develop prostate cancer ${ }^{[12]}$. The incidence of prostate cancer was lowest among Asians (Japanese, 39/100 000 person-years) and Chinese $(28 / 100 \quad 000$ person-

Corresponding Author: Golestan University of Medical sciences-faculty of Meicine-department of biochemistry and Biophysics-gorgan-Golestan province -Iran.Tel:0098-171-4421651, Fax:0098-171-4421289 
years $)^{[13]}$. Cancer registries are available in many countries, but it is important to note that the degree of accuracy may vary. In many countries cancer registries have only recently been established and/or may not cover the whole country, this may explain the low rates of cancer in some reports [14]. In Italy and Spain, prostate cancer incidence, according to estimates in 2000 , was ranked third (approximately $10 \%$ of all new diagnosed cancers), while in France it was the most common male cancer (approximately 19\%) [15].This study was a province-specific estimate of incidence by age groups for prostate cancer in the year 2004.

\section{MATERIALS AND METHODS}

The data used in this study were collected in a cancer registry that was conducted by Health Deputy of Golestan province in IRAN for a period of 1 year (2004). This article focuses on the male cancer registry. Golestan province is located in north of Iran, in the south east of Caspian Sea. The male cancer registry of the Golestan province for different cancer was 409. The collected data included population distribution by gender (male) and age, divided into five-year intervals. The age distribution was collected according to the following age strata: $0-4,5-9,10-14,15-19,20-24,25-$ 29, 30-34, 35-39, 40-44, 45-49, 50-54, 55-59, 60-64, $65-69,70-74,75-79,80-84$ and 85 above. Prostate cancer data was identified and collected in the population based cancer registries through the 18 Pathology Laboratories (where male populations referred to these centers) and using a structured questionnaire, trained personnel conducted in-person interviews to collect information on prostate cancer. in the Golestan province. These were then sent to the Cancer Registry Office of the province and to the cancer registry unit in the Health Deputy. Age-specific rates, annual age-adjusted rates (ASRs) per 100,000 person-years were calculated using the direct methods of standardization to the world population. The data were summarized in a data sheet and coded using the ICD-O. The data were recorded at different levels due to a need for correct registration. This has been done by iarccrgtools-203 software, because it could control the probable problems due to registration at different level.

\section{RESULTS}

A total of 409 males cancer registry from all sites were captured during the one year period, 2004. From this 28 cases were prostate cancer .Prostate cancer incidence rates vary by age .The highest prostate cancer incidence among males in Golestan province was in age 80-84 ( ASR: 215.87/100,000). The prostate cancer incidence according to age specific was as follow: in ages : in ages 0-4, 5-9, 10-14, 15-19, 20-24, 25-29, 30-34, 35-39, 40-44 and 45-49 no prostate cancer incidence(ASR: $0.00 / 100,000$ ), in age 50-54 (ASR: $5.18 / 100,000)$, in age 55-59 no prostate cancer incidence (ASR: 0.00/100,000), in age 60-64 (ASR:10.62/100,000), in age 65-69 (ASR: 18.31/100,000), in age 70-74 (ASR: 107.32/100,000) in age 75-79 (ASR: 70.96/100,000), in age 80-84 (ASR: $215.87 / 100,000)$ and in age above 85 no prostate cancer incidence (ASR: 0.00/100,000). The incidence of prostate cancer in age 80-84 has risen sharply and in age 50-54 incidence of prostate cancer was the lowest (ASR: 5.18/100,000). All diagnosed prostate cancer was adenocarcinoma.

\section{DISCUSSION}

This study presents data and discusses age specific prostate cancer incidence of the numbers of people diagnosed with cancer. The findings of this study showed that prostate cancer is one of the most common cancers in the Golestan province among males. The registry showed that the annual ASR for prostate cancer was 5.17 per 100000 populations in Golestan province. Prostate cancer is a disease predominantly affecting elderly men, and, despite the widespread use of PSA (prostate specific antigen) testing in many countries, the number of deaths from prostate cancer has increased. Compared with most cancers, prostate cancer tends to grow slowly. The prostate cancer is the fifth most common cancer in the world and the second most common in men (19\% in developed countries and 5.3\% in developing countries). Three-quarters of all cases are in men aged 65 or more [16]. Comparison of the ASR for prostate cancer (age specific) among males in Golestan province with those of prostate cancer worldwide show that the Golestan province is also a risk areas like other places in the world. we found that the incidence of prostate cancer rises from age 50 years old (ASR: 5.18/100,000) and is highest in 80-84 years old (ASR: 215.87/100,000). Hsing et al. [6] reviewed data on international trends in prostate cancer incidence and mortality. In the United States, they observed the largest increases in incidence in high-risk countries, especially in younger men. This is probably partly the 
effect of increasing detection of prostate cancer due to use of PSA (prostate specific antigen). But there were also large increases in low-risk countries between 1975 and 1990: 104\% in Singapore, China; 84\% in Miyagi, Japan; 55\% in Hong Kong; and $44 \%$ in Shanghai, China. Some of this may be due to greater awareness of the disease, and diagnosis of small and latent cancers. The early diagnosis of prostate cancer maybe effective to prevent the progress of this cancer. A number of risk factors have been identified for prostate cancer. The most important risk factors are age and risk increases with age. Very few cases are registered in men under 50 and more than $60 \%$ of cases occur in men over 70 years old. The largest number of cases is diagnosed in those aged $70-79^{[17-20]}$. After controlling for age, the greatest increase in risk has generally been associated with a family history of prostate cancer. Risk increases two to three times for men with a family history of prostate cancer in a first-degree relative ${ }^{[11]}$. The high rates of prostate cancer have been associated with the high intake of animal fat ${ }^{[21-22]}$. Clinicians should follow recommended screening guidelines and encourage their patients before age 50 and older (in this area) to have annual PSA testing. The reason for high incidence report in some countries is the use of PSA screening test. On the other hand this report which is explained in methodology is only focused on the registered cases and this can influence in the reported prostate cancer. Clinicians should also ensure that patients at high risk for prostate cancer are identified and offered appropriate referrals and treatment. Continued research is needed on the causes, prevention, and treatment of prostate cancer. In this area the incidence of prostate cancer is started from age 50 years old onward. The age specific prostate cancer maybe is one of the main cause of cancer deaths in Golestan province. According to this information Golestan province harbor a rather incidence for prostate cancer (age specific), comparable to the lower incidence reported in the world.

\section{CONCLUSION}

For the present time it can be said that prostate cancer in males appear to be one of the most prevalent and serious type of cancer in Golestan province and is rising with ageing. Thoughtfully designed epidemiological and clinical studies are pivotal to unravel the details of why and how these are happening and help to plan what should be done to combat effectively with these still deadly diseases. Therefore, further studies to look for the etiology and possible risk factors seem logical.

\section{REFERENCES}

1. Whelan SL, Parkin DM, Masuyer E. 1993. Trends in Cancer Incidence and Mortality. Lyon; France: International Agency for Research on Cancer (IARC) Scientific Publications

2. Naghavi M. 2001.Death in eighteen provinces of Iran. Annual Report of Iranian Ministry of Health and Medical Education;127

3. Iranian Annual of National Cancer Registration Report 2004.Center for Disease control noncommunicable deputy cancer control office; 51

4. WHO. . World health statistics annual 1995, WHO Geneve 1996

5. Jemal A, Murray T, Ward E, et al. 2005. Cancer statistics, 2005. CA Cancer Journal for Clinician;55:10-30

6. Hsing AW, Tsao L, Devesa SS. 2000. International trends and patterns of prostate cancer incidence and mortality. International Journal of Cancer;85:60-7

7. Hsing AW. 2001. Hormones and prostate cancer: what's next? Epidemiological Review;23:42-58

8. Gronberg H. 2003.Prostate cancer epidemiology. Lancet 8; 361(9360): 859-64

9. Parkin DM, Pisani P, Ferlay J. 1999.Estimates of the world-wide incidence of 25 major cancers in 1990. International Journal of Cancer ; 80: 827-41

10. Parkin DM, Bray FI, Devesa SS. 2001. Cancer burden in the year 2000: the global picture. European Journal of Cancer 37 (Suppl. 8): 4-66

11. Parkin DM, Whelan SL, Ferlay J, Teppo L, Thomas DB. 2002.Cancer incidence in Five Continents, Vol. VIII. Lyon, International Agency for Research on Cancer (IARC) Scientific Publications no. 155

12. Gohji K, Nomi M, Egawa S et al. 1997. Detection of prostate carcinoma using prostate specific antigen, its density, and the density of the transition zone in Japanese men with intermediate serum prostate specific antigen concentrations. Cancer 79(10): 1969-76

13. Irvine RA, Yu MC, Ross RK, Coetzee GA. 1995. The CAG and GGC microsatellites of the androgen receptor gene are in linkage disequilibrium in men with prostate cancer. Cancer Research; 55: 19371940 
14. Rooney C, Devis T. 1996. Mortality trends by cause of death in England and Wales 1980-94: the impact of introducing automated cause coding and related changes in 1993. Population Trends 86: 29-35

15. Ferlay J, Bray F, Pisani P, Parkin DM. 2001.GLOBOCAN 2000: Cancer Incidence, Mortality and Prevalence Worldwide, version 1.0. International Agency for Research on Cancer (IARC) Cancer Base no. 5. Lyon, IARC Press

16. D. Max Parkin, MD, Freddie Bray, J. Ferlay and Paola Pisani.2005. Global Cancer Statistics, 2002. CA Cancer Journal for Clinician . 55:74-108

17. Northern Ireland Cancer Registry. Cancer Incidence and Mortality.2006
18. Welsh Cancer Intelligence and Surveillance Unit.2006

19. ISD Online Information and Statistics Division, NHS Scotland. 2006

20. Office for National Statistics, Cancer Statistics registrations:Registrations of cancer diagnosed in 2003, England Series MB1 no.34. ed. Vol. 2005, London: National Statistics

21. Brouwer, I.A., M.B. Katan, and P.L. Zock, 2004.Dietary alpha-linolenic acid is associated with reduced risk of fatal coronary heart disease, but increased prostate cancer risk: a meta-analysis. Journal of Nutrition,. 134(4): p. 919-22

22. Leitzmann, M.F., et al., 2004.Dietary intake of n-3 and $n-6$ fatty acids and the risk of prostate cancer. American Journal of Clinical Nutrition,. 80(1): p. 204-16 